\title{
Stability of the LA-i in measuring learning approaches among medical students.
}

\author{
Muhamad Saiful Bahri Yusoff \\ Medical Education Department, School of Medical Sciences, Universiti Sains Malaysia, 16150 Kota Bharu, \\ Kelantan, Malaysia
}

\section{ARTICLE INFO}

Received

Accepted

: 07/05/2012

Published

: 23/09/2012

: 01/03/2013

\section{KEYWORD}

Stability

Reliability

Deep learning

Surface learning

Strategic learning

Learning Approaches

\section{ABSTRACT}

Introduction: The LA-i was found to be valid, reliable, simple and easy to be administered and consumed minimal time. However, to author knowledge, none of articles reported its stability across multiple observations. Realising its potential, continued research is required to optimize its role, usefulness and applicability as a tool to help educators to understand their students' learning approaches. Objective: To determine stability of the LA-i to measure characteristics of students' learning approaches at different time and occasions in a sample of medical students. Method: A prospective cohort study was done on 177 first year medical students. It was administered to a cohort of medical students at four different intervals. The Cronbach's alpha and intra-class correlation analysis were applied to measure internal consistency and agreement level across the intervals. The analysis was done using SPSS 18. Result: A total of 157 $(88.7 \%)$ first year medical students responded completely to the inventory. The overall Cronbach's alpha value of the LA-i at different intervals ranged between 0.79 and 0.92 , The Cronbach's alpha values for surface learning approach subscale ranged between 0.65 and 0.80 . The Cronbach's alpha value for strategic learning approach subscale ranged between 0.76 and 0.84. The Cronbach's alpha value for deep learning approach subscale ranged between 0.83 and 0.95 . ICC values for the three learning approach subscales ranged between 0.46 and 0.50 . Conclusion: This study reflected that the LA-i had high level of internal stability to measure students' learning approaches at different time and occasions. Continued research is required to optimize its role, usefulness and applicability at various educational settings. 


\section{Introduction}

The variation between students is almost neverending because each one of them has very unique characters that are strongly influenced by genetic makeup (1). Similar phenomenon happens on students approach to learning where they tend to adopt certain ways of learning that best fit with their belief, ability and capacity. Although each of students is unique, but there are common behaviours being displayed which can be clustered together to form meaningful concepts. Marton and Saljo (2005) have proposed three different approaches to learning which are surface approach, strategic approach and deep approach (2).

Deep learners usually learn through understanding on subjects where their intention is to seek own meaning on the subjects to enhance understanding and mastery (2-5).They love to validate information given to them prior to accepting it through relating to previous knowledge and searching for evidence. Their learning is driven by intrinsic motivation where they want to master the subjects so that they can use it for good as well as to teach and share with others. They always monitoring, updating and evaluating their understanding through selfdirected and life-long learning. It is worth noting that, studies have reported that high academic achievement and performance can be predicted from students who adopt deep approach to learning either alone or in combination with strategic approach (6-8).Students who adopt strategic approach to learning commonly learn through systematic or smart study where they are bound to the syllabus of course and their intention is to attain the highest marks as possible (2-5). They are usually competing with other learners to get top rank in the course and are reluctant to share information with others. They stick to time and plan as well as monitor their study progress to ensure every course objectives have been read and understood. Students who adopt strategic approach in combination with deep approach tend to attain high academic success (6-8).
Students who adopt surface approach commonly learn through memorizing facts from the books they read and from lectures they attended (2-5). Their learning driven by extrinsic motivation where they learn due to fear of failure, they want to pass examination and get job. Their intention is just to pass and getting thing done with minimal efforts. Most of the time they accept all the information obtained from books and lecturers unquestioning. Studies have revealed that surface approach to learning has consistently been found to negatively correlate with academic performance and achievement (6, 8, 9). The implications of the learning approaches are significant in considering i) what can educators do to encourage students to adopt deep learning approach, ii) what can educators do to discourage students to adopt surface learning approach and iii) how educators might most effectively facilitate students to fruitful learning. Therefore, understanding the characteristics of students' learning approaches will be advantages for educators to enhance their students' learning experience $(10,11)$.

In order to help educators to understand their students' learning approaches, a stable instrument to measure those characteristics is important. One of the instruments to help educators understand the students' learning approaches is the Learning Approaches Inventory (LA-i) $(12,13)$. The LA-i is a new and promising tool that may be helpful for educators to understand their students' learning approaches. In addition, the LA-i was found to be reliable, valid, simple (i.e. 12 items and 9 items), easy to be understood and administered, and consumed minimal time (12). Realising its potential, further research is required to optimize its role and usefulness as an instrument to help educators to know about their students' learning approaches. Reliability refers to consistency or reproducibility of a measurement over time and occasions $(14,15)$. It is gauged in the form of internal consistency and stability (14-16); without consistency and stability, measurement is compromised. The internal consistency reflects the extent to which items of a test measure various aspects of the same attributes and it is measured by various ways such as 
Cronbach's alpha, Kuder-Richardson and split halves (15).

Stability is measured by the degree of agreement between observations based on multiple administrations in the form of inter-rater reliability, intra-rater reliability and test-retest reliability (15). The degree of agreement between multiple observations can be gauged as correlation coefficients such as intraclass correlation coefficient (ICC) and kappa Cohen coefficient $(14,17,18)$. A previous study reported that the Cronbach's alpha values for the three subscales of LA-i (i.e. surface, strategic and deep learning approach subscales) ranged between 0.69 and 0.89 (12), indicating good level of internal consistency. However, to author knowledge, none of articles reported its stability across multiple observations; therefore, this was conducted to fill in the gap. It should be reminded that stability is one of important qualities that any instrument must be tested to ensure the measurement obtained is reproducible over time and occasion.

This study was designed to answers three questions; 1) what is Cronbach's alpha value of the LA-i over multiple administrations? 2) What is Cronbach's alpha value of LA-i subscales over multiple administrations? 3) What is degree of agreement between measurements of the subscales over multiple administrations? The author postulated that the LA-i would demonstrate good level of stability and internal consistency to measure learning approaches characteristics across time and occasions. This study will provide evidence for its stability to measure the characteristics of students' learning approaches.

\section{Method}

A prospective study was conducted on first year medical students in a Malaysian public medical school. Purposive sampling method was applied and a total of 177 medical students were selected. They were then followed up at four intervals. The researcher obtained permission and clearance from the School of Medical
Sciences and Human Ethical Committee of Universiti Sains Malaysia prior to the study start.

\section{The Learning Approaches Inventory (LA-i)}

It was developed based on the surface, strategic and deep learning approaches theory $(2,12)$. It has two versions which are the original version consists of 12 statements and the shortest version consists of nine statements represent the characteristics of the three learning approaches $(2,3,12,13)$. Each statement was rated using 5likert scores ( $1=$ least like you, $2=$ in between scores of 1 and $3,3=50 \%$ like you, $4=$ in between scores of 3 and 5, 5=most like you) to indicate how close the statement described the respondents' behaviour $(12,13)$. It consists of three subscales (i.e. surface, strategic and deep) and each subscale consists of four statements.

\section{Collection of data}

The LA-i was administered at four intervals; 2 months (time 1), 4 months (time 2), 6 months (time 3) and 8 months (time 4) of the first year medical training. Informed consent was obtained from the respondents and they were asked to response to all statements completely. Data was collected by guided self-administered questionnaire during face-to-face sessions in a hall. The questionnaires were immediately returned after they completely filled in. Data was analysed by Statistical Package for Social Sciences (SPSS) version 18.

\section{Stability analysis}

Reliability analysis was applied to determine the internal consistency of the LA-i. Internal consistency of its items was measured using Cronbach's alpha coefficient. The items were considered to represent an acceptable level of internal consistency if the Cronbach's alpha value within 0.5 to 0.7 and good level if the Cronbach's alpha value more than 0.7 (14-16).

Intra-class correlation (ICC) analysis was done to determine level of agreement between measurements at four different intervals.

The agreement level was represented as ICC coefficient. The ICC coefficient value less than 
0.2 was considered as poor agreement, 0.21 to 0.40 was considered as fair agreement, 0.41 to 0.60 was considered as moderate agreement, 0.61 to 0.80 was considered as good agreement and 0.81 to 1.0 was considered as very good agreement $(14,15,17)$.

\section{Result}

A total of 157 (88.7\%) applicants responded to this study. Majority of the respondents were female $(67.5 \%)$, Malay (45.9\%), came from the matriculation stream (74.5\%) and Muslim (48.4\%) as shown in the table 1.

Table 1 : Demographic profile of participants.

\begin{tabular}{|l|l|r|}
\hline \multicolumn{2}{|c|}{ Variable } & $\begin{array}{r}\text { Frequency (\%), } \\
\text { (N=157) }\end{array}$ \\
\hline Gender & Male & $51(32.5)$ \\
& Female & $106(67.5)$ \\
\hline Race & Malay & $72(45.9)$ \\
& Chinese & $61(38.9)$ \\
& Indian & $19(12.1)$ \\
& Others & $5(3.2)$ \\
\hline Entry qualification & Matriculation & $117(74.5)$ \\
& HSC & $26(16.6)$ \\
& Other & $14(8.9)$ \\
\hline Religion & Islam & $76(48.4)$ \\
& Buddha & $48(30.6)$ \\
& Hindu & $17(10.8)$ \\
& Christian & $12(7.6)$ \\
& Others & $4(2.5)$ \\
\hline
\end{tabular}

Table 2: Internal consistency and ICC values across measurements taken at four different intervals.

\begin{tabular}{|l|l|l|l|l|l|l|l|}
\hline \multirow{2}{*}{ Learning approaches } & \multicolumn{6}{|l|}{ Cronbach's Alpha value } & \multicolumn{2}{l|}{$\begin{array}{l}\text { ICC } \\
\text { value }\end{array}$} \\
\cline { 2 - 8 } & LA-i-12 & LA-i-9 & $\begin{array}{l}\text { Time 1 } \\
(\mathbf{n}= \\
\mathbf{1 5 7 )}\end{array}$ & $\begin{array}{l}\text { Time 2 } \\
(\mathbf{n}= \\
\mathbf{1 5 7 )}\end{array}$ & $\begin{array}{l}\text { Time 3 } \\
(\mathbf{n = 1 5 7})\end{array}$ & $\begin{array}{l}\text { Time 4 } \\
(\mathbf{n = 1 5 7})\end{array}$ & \\
\hline Overall & 0.87 & 0.86 & 0.79 & 0.79 & 0.86 & 0.92 & NA \\
\hline Surface & 0.69 & 0.62 & 0.65 & 0.65 & 0.78 & 0.80 & $0.49^{* *}$ \\
\hline Strategic & 0.81 & 0.73 & 0.76 & 0.76 & 0.79 & 0.84 & $0.50^{* *}$ \\
\hline Deep & 0.89 & 0.88 & 0.83 & 0.83 & 0.93 & 0.95 & $0.46^{* *}$ \\
\hline
\end{tabular}

${ }^{\text {a }}$ ICC analysis (single measure) between $1^{\text {st }}, 2^{\text {nd }}, 3^{\text {rd }} \& 4^{\text {th }}$ administration $* *$ p $<0.001$ LA-i-12 = Learning Approaches Inventory 12 items (12)

LA-i-9 = Learning Approaches Inventory 9 items (12)

Reliability analysis (table 2) showed that the overall Cronbach's alpha value of the LA-i at different intervals ranged between 0.79 and 0.92 , indicating acceptable to good level of internal consistency over time and occasions. The Cronbach's alpha value for surface learning approach subscale ranged between 0.65 and 0.80 , indicating good level of internal consistency over different measurements. The Cronbach's alpha value for strategic learning approach subscale ranged between 0.76 and 0.84 , indicating good level of internal consistency across the intervals. 
The Cronbach's alpha value for deep learning approach subscale ranged between 0.83 and 0.95 , indicating good level of internal consistency across the intervals. ICC analysis (table 2) showed that ICC coefficient values for the three learning approach subscales ranged between 0.46 and 0.50, indicating acceptable level of agreement between the four different measurements.

\section{Discussion}

In general, our data found that the LA-i demonstrated high level of internal consistency over multiple administrations as the overall Cronbach's alpha value more than 0.7 (14-16). This suggested that it had high level of internal stability over multiple measurements at different time and places. On top of that, our finding was comparable with a previous study that reported the overall Cronbach's alpha value ranged between 0.86 and 0.87 (12). In general, our data provided evidence to support the LA-i was a stable instrument to measure students' learning approaches across multiple measurements.

Our data also demonstrated that the three subscales had a good level of internal consistency across multiple administrations; the Cronbach's alpha values ranged between 0.65 and 0.95. This finding suggested that they had a stable internal consistency across occasions and time, reflecting the reproducibility of measurements over time and occasions (15). In addition, this finding is comparable with a previous study which found that Cronbach's alpha values of the subscales ranged from 0.62 to 0.89 (12).

These findings provided evidence to support the stability of the LA-i subscales in measuring students' learning approaches.

On further analysis, the LA-i subscales demonstrated acceptable level of agreement between measurements at different time and occasions as the ICC coefficient values more than $0.40(15,17)$. It reflected acceptable degree of agreement between the LA-i subscales measurements over multiple administrations at different time and occasions. In other word, the subscales showed an ability to produce similar results for similar individual at different time and occasions. These findings clearly demonstrated that the subscales have acceptable level of stability to measure characteristics of students' learning approaches across time and occasions.

The reliability analysis has provided evidence of its internal stability in measuring students' learning approaches across time and occasions. Despite these encouraging findings, this study has several limitations that should be considered for future research as well as for interpretation. The first, this study was conducted on first year medical students at a medical school, so, any attempt to generalise this finding should made with caution. The second, this study used purposive sampling method to select study subjects therefore it may lead to sampling bias that might compromise authenticity of the current findings.

Therefore, better sampling such as random sampling should be used in future research to minimise the sampling bias. Considering these limitations, interpretation of the findings should be done with caution. Apart from that, this is the first study reported the stability of the LA-i based on more than three measurements at different time and occasions. Continued research is required to optimise its role, usefulness and applicability to measure students' learning approaches.

\section{Conclusion}

This study reflected that the LA-i had high level of internal stability to measure students' learning approaches at different time and occasions. Continued research is required to optimize its role, usefulness and applicability at various educational settings.

\section{Acknowledgement}

Our special thanks to the School of Medical Sciences, Universiti Sains Malaysia for supporting and allowing us undertake this study. Our appreciation to all the first year medical students involved in this study. Our special 
thank you also to the support staff of the Academic Office and Medical Education Department staff for their help. This study was made possible under the Short Term Research Grant 304/PPSP/6139071.

\section{Reference}

1. Sheperd P. Personality matters: The whole brain approach, why we learn, think and behave. Malaysia: Brain Works Media; 2007.

2. Marton F, Saljo R. Approaches to learning. In: Marton F, Hounsel D, Entwistle N, editors. The experience of learning: Implications for teaching and studying in higher education. 3rd ed. Edinburgh: Universiti of Edinburgh, Centre for Teaching, Learning and Assessment; 2005. p. 41-58.

3. Yusoff MSB, Abdul Rahim AF. The Study Skills Workshop2010: Available from: http://services.aamc.org/30/mededportal/serv let/s/segment/mededportal/?subid=8010.

4. Biggs JB. Student approaches to learning and studying. Melbourne: Australian Council for Educational Research; 1987.

5. Felder RM, Brent R. Understanding student differences. Journal of Engineering Education. 2005;94(1):57-72.

6. Boyle EA, Duffy T, Dunleavy K. Learning styles and academic outcome: The validity and utility of Vermunt's Inventory of Learning Styles in a British higher education setting. British Journal of Educational Psychology. 2003;73:267-90.

7. Chamorro-Premuzic T, Furnham A. Personality, intelligence and approaches to learning as predictors of academic performance. Personality \& Individual Differences. 2008;44:1596-603.

8. Diseth A. Personality and approaches to learning as predictors of academic achievement. European Journal of Personality. 2003;17:143-55.

9. Diseth A, Martinsen O. Approaches to learning, cognitive styles, and motives as predictors of academic achievement. Educational Pyschology. 2003;23:195-207.

10. Dent JA, Harden RM. A practical guide for medical teachers. UK: Churchill Livingstone; 2009.

11. Newble D, Cannon R, Kapelis Z. A handbook for medical teachers: Kluwer Academic Publishers; 2001.
12. Yusoff MSB. Psychometric Properties of the Learning Approach Inventory: A Confirmatory Factor Analysis. Education in Medicine Journal. 2011;3(2):e24-e31.

13. Yusoff MSB. Evaluation of internal consistency and construct validity of the Learning Approach Inventory (LA-i) among medical students. International Medical Journal, 2012; 19 (2): 181-182.

14. Altman DG. Practical statistics for medical research. London: Chapman and Hall; 1991.

15. Streiner LD, Norman GR. Health Measurement Scales: A Practical Guide to Their Development and Use. 4th ed. New York: Oxford University Press; 2008.

16. Nunally JC. Psychometric theory. 2nd ed. New York: McGraw Hill; 1978.

17. Landis JR, Koch GG. The measurement of observer agreement for categorical data. Biometrics. 1977:159-74.

18. Shrout PE, Fleis JF. Intraclass correlations: uses in assessing rater reliability. Psychological Bulletin. 1979;86(2):420-8. 